\title{
ANALIZA MOŻLIWOŚCI OGRANICZENIA ZUŻYCIA ENERGII ELEKTRYCZNEJ SYSTEMU ZAOPATRZENIA W WODE NA PRZYKŁADZIE STACJI UZDATNIANIA WODY ,KAROLIN" W OLSZTYNIE
}

\begin{abstract}
Szacuje się, że systemy zaopatrzenia ludności w wodę mogą pochłaniać nawet do 7\% energii wykorzystywanej przez społeczeństwo. Głównym elementem odpowiedzialnym za tak duże zużycie energii elektrycznej są pompy tłoczące wodę. Zazwyczaj poprawa efektywności energetycznej pracującej pompy lub zespołu pomp, pociąga za sobą duże koszty inwestycyjne. Spojrzenie kompleksowe na funkcjonowanie całego systemu, często pozwala na zmniejszenie zużycia energii przez system bez ponoszenia dodatkowych nakładów finansowych. To jakiego rzędu będą to oszczędności zależy wyłącznie od specyfiki przedsiębiorstwa. W pracy przedstawiono analizę energetyczną wybranego miesiąca pracy ujęcia wody surowej dla Stacji Uzdatniania Wody Karolin w Olsztynie. Za wskaźnik efektywności energetycznej pracujących pomp na ujęciu przyjęto jednostkowe zużycie energii. Na podstawie przeprowadzonej analizy stwierdzono słabą zależność pomiędzy czasem pracy poszczególnych pomp w analizowanym okresie a jednostkowym zużyciem energii. Przeprowadzona symulacja pracy ujęcia, w której uwzględniono zwiększone obciążenie pomp najefektywniejszych, pokazała możliwość zmniejszenia zużycia energii elektrycznej o około $12 \%$.
\end{abstract}

Słowa kluczowe: efektywność energetyczna, oszczędzanie energii, stacja uzdatniania wody, pompy

\footnotetext{
1 Autor do korespondencji / corresponding author: Michał Duda, Uniwersytet Warmińsko-Mazurski w Olsztynie, Katedra Elektrotechniki Energetyki Elektroniki i Automatyki, ul. Oczapowskiego 11, 10-719 Olsztyn; tel. 89 524-61-57; michal.duda@uwm.edu.pl

2 Daniel Chludziński, Uniwersytet Warmińsko-Mazurski w Olsztynie, Katedra Elektrotechniki Energetyki Elektroniki i Automatyki, ul. Oczapowskiego 11, 10-719 Olsztyn; tel.; tel. 89 524-61-57; daniel.chludzinski@uwm.edu.pl
} 


\section{Wprowadzenie}

Za podstawę funkcjonowania systemu zaopatrzenia w wodę (SZW) należy przyjąć niezawodność działania, która polega na możliwości dostarczenia wody do miejsc jej użytkowania w niezbędnej ilości o wymaganych parametrach jakościowych i określonym ciśnieniu [1] oraz koszcie akceptowalnym zarówno dla producenta i odbiorcy[2].

Z uwagi na interakcję czynników technicznych, czynników związanych z otoczeniem i środowiskiem, SZW określa się mianem systemu biotechnicznego. Według [3] do cech specyficznych SZW można zaliczyć: złożoność systemu, losowy charakter zdarzeń wpływający na funkcjonowanie systemu, duży stopień automatyzacji i komputeryzacji systemu oraz występowanie zmiennych struktur niezawodnościowych (nadmiar lub niedobór wody, ciśnienie dzienne i nocne itp.).

Struktura systemu zaopatrzenia w wodę może być mniej lub bardziej rozbudowana. Podstawowe składowe SZW to: podsystem ujmowania wody, podsystem pompowania wody do stacji, podsystem uzdatniania wody i podsystem dystrybucji [4]. Nieodzownym elementem każdego z tych podsystemów jest transport cieczy. Proces ten uznawany jest za energochłonny, jak szacuje się może pochłaniać znaczne ilości energii elektrycznej, oceniane na $20-30 \%$ całej produkcji [5], a w przypadku transportu wody może stanowić nawet 7\% całkowitej energii zużywanej przez społeczeństwo [6]. Straty występujące w układach pompowych wg [5] można podzielić na nieuniknione (sprawność procesów rzeczywistych poniżej 100\%) i niepotrzebne typu: niewłaściwie zaprojektowany system, błędy w doborze urządzeń, czy też zła eksploatacja. Gro przyczyn powstawania strat niepotrzebnych jest trudne do wyeliminowania wskutek braku możliwości sfinansowania kompleksowej modernizacji systemu, ale z uwagi na skalę, zagadnienie pozostaje nadal aktualne. Propozycje metod optymalizacji, a tym samym poprawy efektywności energetycznej SZW przedstawiono w pracach $[1,6,7,8]$.

\section{Stacja uzdatniania wody „Karolin”}

Stacja uzdatnia wody (SUW) „Karolin” jest jedną z pięciu i zarazem największą stacją wchodzącą w skład systemu zaopatrzenia w wodę miasta Olsztyn i kilku ościennych miejscowości. Stacja może dostarczyć do $32000 \mathrm{~m}^{3}$ wody na dobę, gdzie wszystkie razem ujęcia pozyskują do $59000 \mathrm{~m}^{3} /$ dobę wody. Woda do SUW Karolin pobierana jest z ujęcia Wadąg oddalonego o $3 \mathrm{~km}$ od stacji. W skład ujęcia wchodzi 19 studni głębinowych o łącznej wydajności $1350 \mathrm{~m}^{3} / \mathrm{h}$ podłączonych do jednego rurociągu zbiorczego. Woda z ujęcia do stacji tłoczona jest bezpośrednio przez pompy głębinowe. Rozmieszczenie studni oraz schemat ich połączenia przedstawiono na rysunku 1. 


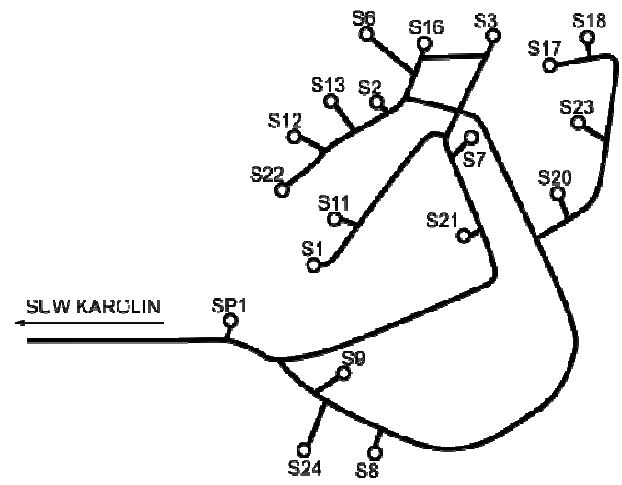

Rys. 1. Ujęcie wody „Wadąg” - rozmieszczenie studni i schemat połączeń

Fig. 1. Water intake „Wadąg” - equipment location and circuit diagram

Wydajność ujęcia Wadąg regulowana jest poprzez włączanie dodatkowych lub wyłączanie pracujących studni. Zazwyczaj pracuje dziesięć z dziewiętnastu pomp głębinowych, ponieważ średnie zapotrzebowanie miejskiej sieci wodociągowej ze stacji Karolin wynosi $680 \mathrm{~m}^{3} / \mathrm{h}$, co stanowi około $50 \%$ wydajności ujęcia Wadąg. Pozyskiwana woda z ujęcia, należy do wód średnio twardych, zawiera ponadnormatywną ilość związków żelaza i manganu, natomiast pod względem bakteriologicznym spełnia normy i nie wymaga chlorowania. Schemat procesu technologicznego uzdatnia wody w SUW Karolin przedstawiono na rysun$\mathrm{ku} 2$. Woda surowa $\mathrm{z}$ ujęcia w pierwszej kolejności trafia na dwa aeratory, gdzie przeprowadzany jest proces napowietrzania. Następnie z aeratorów kierowana jest na pierwszy stopień filtracji w celu usunięcia tlenków żelaza, po czym przepuszczana jest przez filtry drugiego stopnia tak zwane odmanganiacze. Po filtracji, uzdatniona woda gromadzona jest w dwóch podziemnych zbiornikach o pojemności $3000 \mathrm{~m}^{3}$ każdy.

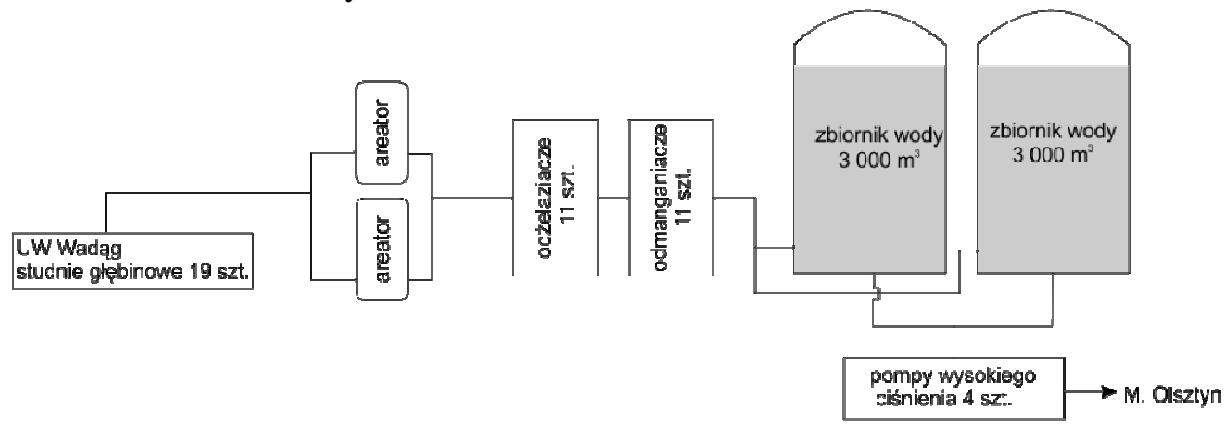

Rys. 2. Schemat procesu technologicznego uzdatniania wody SUW „Karolin”

Fig. 2. Water treatment station "Karolin": schematic of the technological process 
Dystrybucja uzdatnionej wody z podziemnych zbiorników do miejskiej sieci wodociągowej odbywa się za pośrednictwem dwóch pomp wysokiego ciśnienia. Pompy ustawione są na utrzymywanie stałego ciśnienia, a ich wydajność jest płynnie regulowana za pomocą falowników. W celu zabezpieczenia przed ewentualną awarią podsystemu dystrybucji wody, stacja wyposażona jest w cztery pompy tłoczące wodę do miasta, przy czym zwykle pracują dwie, a w nocy tylko jedna.

\section{Analiza i dyskusja wyników}

$\mathrm{Na}$ potrzeby przeprowadzenia analizy energetycznej proces zaopatrzenia w wodę miasta Olsztyn przez SUW Karolin podzielono na trzy etapy:

- etap 1 - ujęcie wody surowej,

- etap 2 - filtracja (uzdatnianie wody surowej),

- etap 3 - dystrybucja wody do miejskiej sieci wodociągowej.

Analizując moc elektryczną zainstalowanych urządzeń i czas ich pracy, oszacowano wstępnie udział procentowy zużycia energii elektrycznej na poszczególnych etapach produkcji wody. Z przeprowadzonej oceny wynika, że najbardziej energochłonny jest etap dystrybucji, który pochłania około 50\% energii elektrycznej zużywanej przez zakład w realizowanym procesie. Równie energochłonny jest etap poboru wody $46 \%$ ogólnego zużycia energii, natomiast uzdatnianie wody (filtracja) pochłania jedynie $4 \%$ energii elektrycznej zużywanej w procesie [9].

Ze względu, iż w Stacji dystrybucja wody jest realizowana przez nowoczesne pompy z płynną regulacją obrotów, a ilość energii związana z filtracją jest niewielka, analizę możliwości ograniczenia zużycia energii zawężono do etapu ujęcia wody surowej. We wspomnianym etapie, zużycie energii związane jest z pracą 19 pomp głębinowych, których wydatek cieczy regulowany jest poprzez dławienie przepływu w zależności od zalecanej wydajności studni.

Za wskaźnik oceny energetycznej pracy pomp głębinowych przyjęto jednostkowe zużycie energii przetłaczania $1 \mathrm{~m}^{3}$ cieczy - wzór (1) [5],

$$
e=\frac{\Sigma E}{\Sigma Q}
$$

gdzie: $\Sigma Q-$ ilość cieczy przetłoczonej przez obiekt pompowy $\left[\mathrm{m}^{3}\right]$,

$\Sigma E$ - ilość energii zużyta do przetłoczenia $\Sigma Q$ cieczy [kWh].

Analizę przeprowadzono na podstawie aktualnego, miesięcznego zapisu parametrów pracy ujęcia Wadąg (kwiecień 2016 r.). Obliczona wartość jednostkowego zużycia energii dla poszczególnych pomp zawiera się $\mathrm{w}$ zakresie od $0,24 \mathrm{kWh} / \mathrm{m}^{3}$ (studnia SW24) do $0,56 \mathrm{kWh} / \mathrm{m}^{3}$ (studnia S22). Różnica między skrajnymi wartościami jednostkowego zużycia energii jest ponad dwukrotna, co 
wskazuje na to iż, znaczący wpływ na całkowitą ilość zużytej energii może mieć wybór studni oraz czas jej pracy. Czas pracy i jednostkowe zużycie energii poszczególnych pomp głębinowych ujęcia Wadąg pracujących w miesiącu kwietniu przedstawiono na rysunku 3 , gdzie linią przerywaną zaznaczono wartość średnią jednostkowego zużycia energii. Jak można zauważyć, nie widać bezpośredniej zależności czasu pracy poszczególnych pomp i ich jednostkowego zużycia energii. Współczynnik korelacji w analizowanym przypadku jest ujemny i wyniósł - 0,2. Wskazuje to na bardzo słabą zależność czasu pracy i jednostkowego zużycia energii poszczególnych pomp na ujęciu.

W rozpatrywanym miesiącu pompy głębinowe $\mathrm{z}$ ujęcia Wadąg przetłoczyły $461520 \mathrm{~m}^{3}$ wody zużywając przy tym $158040 \mathrm{kWh}$, co daje $0,34 \mathrm{kWh}$ zużytej energii elektrycznej na $1 \mathrm{~m}^{3}$. Wartość ta jest mniejsza od średniej wartości jednostkowego zużycia energii elektrycznej wyznaczonej dla pomp głębinowych pracujących w miesiącu kwietniu, która wyniosła $0,35 \mathrm{kWh} / \mathrm{m}^{3}$.

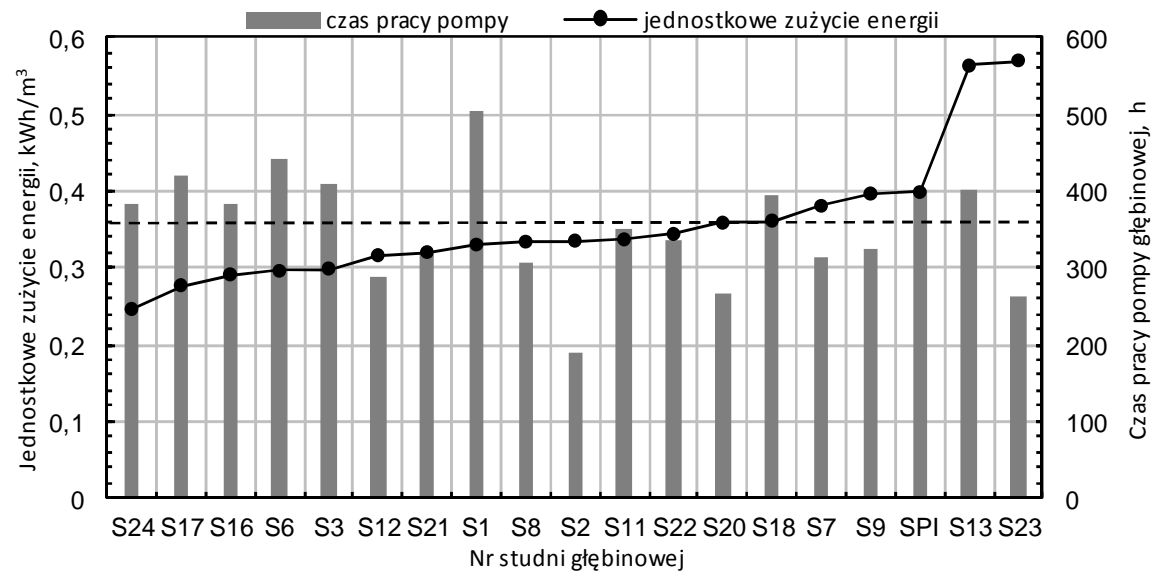

Rys. 3. Jednostkowe zużycie energii elektrycznej oraz czas pracy pomp

Fig. 3. The specific electricity consumption and water pumps working time

W analizowanym okresie, można zauważyć dobowe zmiany jednostkowego zużycia energii ujęcia (Rys. 4 ). Co prawda zróżnicowanie zmienności tej wielkości jest raczej słabe - klasyczny współczynnik zmienności KWZ $=5 \%$. Odnosząc jednakże różnicę wartości maksymalnej wynoszącej $0,39 \mathrm{kWh} / \mathrm{m}^{3}$ i minimalnej $0,32 \mathrm{kWh} / \mathrm{m}^{3}$ do ilości wody pobranej z ujęcia $\mathrm{w}$ analizowanym miesiącu otrzymujemy o $32300 \mathrm{kWh}$ zmniejszone zużycie energii elektrycznej. Z kolei porównując najbardziej i najmniej efektywny dzień pracy pomp głębinowych i biorąc przy tym średnią wydajność ujęcia, różnica zużytej energii to około $1058 \mathrm{kWh}$ na dobę. 


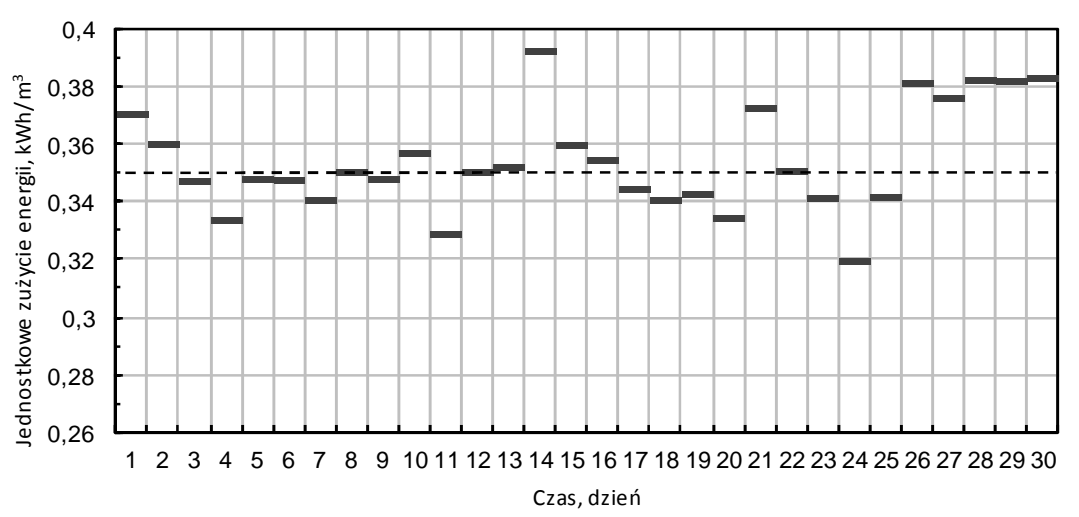

Rys. 4. Jednostkowe zużycie energii elektrycznej ujęcia Wadąg (kwiecień 2016)

Fig. 4. The water intake "Wadąg" specific electricity consumption in April 2016

Prawidłowa eksploatacja ujęcia wyklucza pracę wyłącznie najefektywniejszych studni, ponieważ zbyt długi czas przestoju studni obniża jej wydajność. W przypadku analizowanego ujęcia przyjęte jest, że czas przestoju studni w okresie letnim nie powinien przekraczać pięciu dni, a w zimowym dwóch dni. Uwzględniając powyższe i przy zwróceniu szczególnej uwagi na jednostkowe zużycie energii poszczególnych pomp, opracowano przykładowy harmonogram pracy studni zapewniający pozyskanie takiej samej ilości wody z ujęcia jak w analizowanym miesiącu. Czynnikami, które są równie istotne przy tworzeniu harmonogramu pracy studni a nie zostały uwzględnione w opracowanym harmonogramie, jest nakładanie się lei depresji (zjawisko podbierania wody przez studnie) oraz zjawisko wzajemnego dławienia się pomp wskutek tłoczenia wody do wspólnego rurociągu.

W miesiącu kwietniu pozyskano z ujęcia Wadąg $461520 \mathrm{~m}^{3}$ wody kosztem zużycia $163282 \mathrm{kWh}$ energii elektrycznej. Według opracowanego, optymalnego harmonogramu taką samą ilość wody można pozyskać z ujęcia zużywając 143100 kWh energii elektrycznej i zaoszczędzając w ten sposób 20182 kWh energii. Zakładając, że proponowany harmonogram pracy ujęcia wody może być realizowany tylko $\mathrm{w}$ okresie gdy temperatura otoczenia jest powyżej $0^{\circ} \mathrm{C}$, czyli około siedmiu miesięcy w roku (od kwietnia do listopada), daje to potencjalną oszczędność na poziomie $140000 \mathrm{kWh}$. Przy jednostkowej cenie energii elektrycznej 0,5 zł za $1 \mathrm{kWh}$, można zaoszczędzić blisko $70000 \mathrm{zł}$ rocznie.

$\mathrm{Na}$ rysunku 5 przedstawiono jednostkowe zużycie energii elektrycznej przez zestaw pompowy pracujący w danej dobie - przykładowy wariant optymalny. Linią przerywaną zaznaczono wartość średnią jednostkowego zużycia energii ujęcia w miesiącu kwietniu, natomiast linia wypunktowana przedstawia średnie jednostkowe zużycie energii ujęcia dla wariantu optymalnego.

Rozpatrując uzyskaną oszczędność energii elektrycznej w aspekcie pozyskania takiej samej ilości energii elektrycznej z instalacji fotowoltaicznej, przy 
założeniu średniorocznej produkcji energii z $1 \mathrm{kWp}$ na poziomie $1000 \mathrm{kWh}$ [10] należy zainstalować ogniwa fotowoltaiczne o mocy $140 \mathrm{kWp}$. Uwzględniając cenę $1 \mathrm{kWp}$ na poziomie 5800 zł [11], koszt takiej instalacji wyniósłby $812000 \mathrm{zl}$.

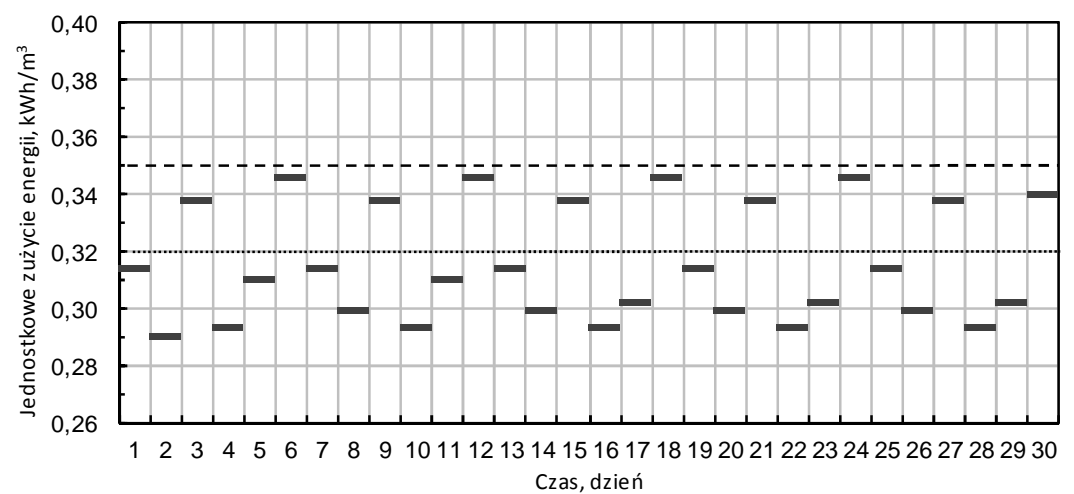

Rys. 5. Jednostkowe zużycie energii elektrycznej ujęcia „Wadąg” - wariant optymalny

Fig. 5. The water intake "Wadąg" specific electricity consumption - optimum variant

\section{Podsumowanie}

Przeprowadzona analiza energetyczna wskazuje na występowanie potencjalnych możliwości zaoszczędzenia energii elektrycznej w podsystemie ujęcia wody surowej badanego zakładu. Oszczędności te mogą zostać osiągnięte na drodze optymalizacji harmonogramu pracy studni. Jednakże z uwagi na specyfikę tego podukładu, nie jest możliwe stworzenie uniwersalnego harmonogramu. Przedstawiony $\mathrm{w}$ pracy harmonogram jest teoretycznym rozważaniem, które wymaga weryfikacji niemniej jednak nawet częściowa jego realizacja powinna przynieść wymierne korzyści finansowe przedsiębiorstwu.

Zoptymalizowanie pracy ujęcia wody surowej wymaga bieżącego i pełnego monitoringu wszystkich parametrów studni, co też w najbliższej przyszłości zakład planuje zrealizować poprzez modernizację i rozbudowę obecnego systemu.

\section{Literatura}

[1] Kwietniewski M., Roman M., Kłoss-Trąbaczkiewicz H.: Niezawodność wodociągów i kanalizacji, Wydawnictwo Arkady, Warszawa 1993.

[2] Szymik-Gralewska J., Zimoch I.: Zasady optymalizacji niezawodności eksploatacji stacji uzdatniania wody, Monografia - XXIII Międzynarodowa Konferencja Naukowo - Techniczna „Zaopatrzenie w wodę, jakość i ochrona wód- WODA 2014”, s. $157-178$.

[3] Lubowiecka T. Wieczysty A. Bednarczyk T.: O potrzebie wprowadzenia probabilistycznych metod badania i projektowania systemów zaopatrzenia w wodę, Konferencja Naukowo-Techniczna pt. Aktualne problemy badawcze, projektowe i eksploata- 
cyjne wodociągów i kanalizacji, Wydawca Przedsiębiorstwo INSTAL-compakt Sp. z o.o., Kraków 1995.

[4] Denczew S.: Niezawodność funkcjonowania i niezawodność bezpieczeństwa systemów zaopatrzenia w wodę na przykładzie m. st. Warszawy, Warszawa 2002, files.pwi.edu.pl/files/denczew.doc \{dostęp: 10.05.2016 r.\}.

[5] Jędral W.: Efektywność energetyczna pomp i instalacji pompowych. Krajowa Agencja Poszanowania Energii S.A., Warszawa 2007.

[6] Coelho, B.; Andrade-Campos, A.: Efficiency achievement in water supply systemsA review. Efficiency achievement in water supply systems - A review, vol. 30, 2014, pp. 59-84.

[7] Feldman M.: Aspects of energy efficiency in water supply systems. In: Proceedings of the $5^{\text {th }}$ IWA Water Loss Reduction Specialist Conference, South Africa, 2009.

[8] Piechocki J., Jaroszewska E.: Wykorzystanie OZE do zasilania zespołów pompowych wody pitnej w układach hybrydowych, Wodociągi - Kanalizacja, NR 5(135)/2015, s. 52-53.

[9] Blajer M.:Analiza energetyczna procesu uzdatniania wody w stacji "Karolin" - studium przypadku, Praca inżynierska, 2016, Uniwersytet Warmińsko-Mazurski w Olsztynie, Wydział Nauk Technicznych.

[10] Mirowski T., Sornek K.: Potencjał energetyki prosumenckiej w Polsce na przykładzie mikroinstalacji fotowoltaicznych $\mathrm{w}$ budownictwie indywidualnym, Polityka Energetyczna - Energy Policy Journal, 2(18)/2015, s. 73-84.

[11] http://fotowoltaika.corab.eu \{dostęp: 10.05.2016 r.\}.

\section{ANALYSIS TO REDUCE ELECTRICITY CONSUMPTION IN WATER SUPPLY SYSTEM, CASE STUDY: WATER TREATMENT STATION "KAROLIN" IN OLSZTYN}

\section{S u m m a r y}

Is estimated that water supply networks responses for around $7 \%$ total electricity consumed by society. The water pumps are the most energy consuming equipment of the network. Usually, the energy efficiency improvement of working water pump (or pump's group) leads to significant investment costs. The complex view on the whole water supply system can reduce electricity consumption without any additional costs. The savings magnitude depends on the water supply company specification. This work presents the analysis of water intake working in one chosen month. Case study was involved for water treatment station "Karolin" in Olsztyn. The specific energy consumption was hired as the water pumps energy efficiency indicator. The analysis proved the weakly dependence of water pumps working time and the specific energy consumption. Based on the water intake working simulation with condition of increasing the workload of the most efficient water pumps stated that the electricity reduction possibility is $12 \%$ of total consumption.

Keywords: energy efficiency, energy saving, water treatment system, water pumps

DOI: $10.7862 / \mathrm{rb} .2016 .252$

Przestano do redakcji: $30.06 .2016 r$.

Przyjęto do druku: 20.12.2016 r. 